\title{
Perceção Comparada entre Consulentes e seus Médicos Quanto à Empatia Médica
}

Luísa Fonte*, Luiz Miguel Santiago**

Pontos salientes do trabalho:

- A empatia médica, atributo cognitivo e emocional, tem sido muito debatida na literatura médica. Sendo um característica importante para a melhor consequência em saúde, tanto de consulentes como de médicos, pode ser medida.

- Este estudo traz como conhecimento a subavaliação dos médicos ao valor que os consulentes atribuem à sua atuação empática.

- O ensino da empatia médica em pré e pós-graduado deve ser feito para que os médicos sejam empáticos e, ao mesmo tempo, percebam qual a intensidade com que desempenham a sua função, evitando desgaste desnecessário.

\section{Resumo}

Introdução: A empatia médica é fator promotor de meIhores resultados em saúde e maior satisfação dos consulentes. O nosso objetivo consistiu em avaliar a capacidade dos médicos perceberem o grau de empatia que os seus consulentes percecionam.

Material e Métodos: Estudo observacional e transversal com aplicação da Jefferson Scale of Patient Perceptions of Physician Empathy (JSPPPE) a consulentes, e uma escala idéntica, mas em espelho, a médicos, os últimos quanto à sua perceção da resposta do consulente. Os médicos solicitaram a resposta ao questionário aos três primeiros consulentes de cada dia, também com o registo de dados epidemiológicos do utente. Dados colhidos entre julho e agosto de 2015. Tamanho da amostra calculado para representar o número médio de consultas de uma semana de trabalho (margem de erro 6\%, IC a 95\% e distribuição de resposta de 50\%, com n=201).
Resultados: Amostra de conveniência de 217 pares de questionários. Pontuação global de empatia (média \pm dp; IC a 95\%) para consulentes $(6,5 \pm 0,7 ; 6,4$ a 6,6$)$ e para médicos $(5,5 \pm 0,8 ; 4,8$ a 5,8). Na melhor distribuição percentílica ( $P \geq 75)$, estão $51,2 \%$ das respostas dos consulentes e $32,3 \%$ dos médicos.

Discussão e Conclusão: Apesar de os consulentes parecerem bastante satisfeitos com a relação empática desenvolvida com os seus médicos de família, os profissionais não têm uma perceção semelhante da empatia experienciada pelos seus utentes. Conclui-se que os médicos julgam ter uma relação menos empática com os seus consulentes do que aquilo que estes consideram, sendo necessários mais estudos para explicar esta diferença.

Palavras-chave: “Empatia”, "Relação Médico-Doente”, "JSPPPE”, "Perceção do doente", “"Perceção do médico"

*Interna de Formação Específica de Medicina Geral e Familiar na USF Ponte (ACes Alto Ave, em Guimarães)
${ }^{* *}$ MD, PhD, Professor Faculdade de Medicina da Universidade de Coimbra. Especialista em MGF, Assistente Graduado Sénior, USF Topázio, ACES Baixo Mondego 


\section{Introdução}

Um dos mais importantes atributos para um médico de Medicina Geral e Familiar (MGF) é a capacidade de usar de forma efetiva o conhecimento sobre relações interpessoais no contacto com os doentes, sendo a empatia crucial no desenvolvimento dessas relações terapêuticas. ${ }^{1}$

Hojat define empatia como um "atributo predominantemente cognitivo (em vez de emocional) que envolve a compreensão (em vez do sentimento) das experiências, preocupações e perspetivas do doente, combinada à capacidade de comunicar essa mesma compreensão". ${ }^{2}$ Capacidades de comunicação empática estão associadas a melhores resultados clínicos, maior satisfação dos doentes, maior adesão à terapêutica ${ }^{3}$, e a aumento das capacidades diagnóstica e terapêutica dos médicos. ${ }^{4}$

Somente com a criação da Jefferson Scale of Patient Perception of Physician Empathy (JSPPPE), a primeira escala capaz de avaliar a perceção dos consulentes sobre a empatia do seu médico5, se percebeu que os resultados clínicos se correlacionavam significativamente com essa perspetiva dos consulentes, e não com o auto-relato da empatia por parte do profissional.6 Assim sendo, coloca-se a possibilidade de a perceção do consulente sobre a empatia do seu médico diferir da visão do médico sobre a sua própria empatia. ${ }^{5}$

Nesse sentido, surge a necessidade de avaliar também a capacidade dos médicos sentirem a empatia experienciada pelos seus consulentes, tornando-se útil a validação de um instrumento que, simultaneamente e por comparação, meça a empatia do consulente pelo seu médico, e avalie o que os médicos pensam estar a ser percebido pelos seus consulentes neste aspeto.

O objetivo deste trabalho será dar resposta à seguinte questão: "Conseguem julgar os médicos a empatia sentida pelos seus consulentes?". Coloca-se a hipótese que os médicos tenderão a considerar ter uma relação menos empática do que aquela que os seus consulentes sentem.

\section{Material e Métodos}

Foi obtido parecer favorável da Comissão de Ética da Administração Regional de Saúde do Centro, assim como autorização, juntos dos seus coordenadores, das quatro Unidades de Saúde Familiar (USF) do distrito de Coimbra onde realizamos este projeto: USF Topázio (Eiras),
USF Cruz de Celas (Coimbra), USF Marquês de Marialva (Cantanhede) e USF Araceti (Montemor-o-Velho).

Como o objetivo era a comparação da perceção do consulente com a visão do médico no que toca à empatia experienciada pelo utente, entregamos questionários a utentes e a profissionais. O questionário entregue a cada consulente correspondeu à JSPPPE (cuja validade e características psicométricas estão já demostradas a nível internacional4,6), enquanto que o respondido por cada médico consistiu numa escala em espelho da JSPPPE, objeto de trabalho pelo corpo investigador. Os profissionais preencheram igualmente dados sobre o doente, que permitiram a caracterização sociodemográfica da amostra estudada.

Tratou-se de um estudo observacional e transversal, numa amostra não probabilística e de conveniência, definida como os três primeiros doentes de cada dia de cada médico, até se perfazer o número de questionários entregues a cada profissional. Por cada consulente a quem o médico entregava um questionário, respondia ao seu respetivo, sendo que ambos estavam numerados para posterior emparelhamento e comparação de perceções. O questionário do consulente era depositado pelo próprio em envelope fechado numa caixa junto de funcionários administrativos, sendo o do médico também colocado em envelope próprio e posteriormente reunidos por um responsável em cada unidade. Apenas os investigadores tiveram acesso aos envelopes abertos e questionários emparelhados, garantindo-se deste modo anonimato, sigilo e confidencialidade. Os dados foram colhidos em julho e agosto de 2015.

Calculamos a amostra para uma população de 800 pessoas que em média são atendidas por dia pelas quatro USF onde o estudo foi realizado. Com uma margem de erro de 6\%, nível de confiança de 95\% e distribuição de resposta de 50\%, surge uma amostra de 201 pessoas. Entregamos 310 conjuntos de questionários, compostos pelo questionário do utente e o do médico, distribuídos pelas quatro USF, obtendo 217 conjuntos de questionários válidos.

Após construção da base de dados em Excel, tratámos os dados com recurso a SPSS Software for Windows - version 19.0 (SPSS Inc., Chicago, IL). Realizámos estatística descritiva e análise inferencial, após verificação da normalidade dos dados. Utilizamos o teste t de Student e o coeficiente de correlação de Pearson, e definimos como estatisticamente significativo um valor de $p<0,05$. 


\section{Resultados}

\section{Caracterização da amostra}

A tabela 1 apresenta a caracterização sociodemográfica da amostra, não tendo sido nosso objetivo correlacionar estas variáveis com os resultados de empatia. A amostra engloba $142(65,4 \%)$ consulentes do sexo feminino e 75 (34,6\%) do sexo masculino, estando a maioria, 129 (59,4\%), na faixa etária compreendida entre os 36 e os 65 anos. A média de idades ronda os 54 anos; a mediana é 55 anos e a moda 44 anos. A maioria frequentou a $4^{\mathrm{a}}$ classe ou o $9^{\circ}$ ano $(47,5 \%)$, tinha entre 3 a 5 consultas no último ano (42,9\%) e pelo menos duas patologias crónicas $(69,1 \%)$. Somente $20,7 \%$ tinha problemas sociais crónicos incluídos no capítulo Z da ICPC-2.

Tabela 1: Caracterização da amostra total, com $n=217$ consulentes

\begin{tabular}{|c|c|c|c|}
\hline \multicolumn{2}{|c|}{ n (\%) } & \multicolumn{2}{|c|}{$n(\%)$} \\
\hline Grupo etário & & onsultas no & \\
\hline$\leq 35$ anos & $31(14,3)$ & $\leq 2$ & $77(35,5)$ \\
\hline 36 a 65 anos & $129(59,4)$ & $\geq 3$ e $\leq 5$ & $93(42,9)$ \\
\hline$\geq 66$ anos & $57(26,3)$ & $\geq 6$ & $47(21,7)$ \\
\hline Género & & atologias c & \\
\hline Masculino & $75(34,6)$ & $<2$ & $67(30,9)$ \\
\hline Feminino & $142(65,4)$ & $\geq 2$ & $150(69,1)$ \\
\hline Formação académica & & oblema crór & \\
\hline Sabe ler e escrever & $41(18,9)$ & Sim & $45(20,7)$ \\
\hline $4^{a}$ classe ou $9^{\circ}$ ano & $103(47,5)$ & Não & $172(79,3)$ \\
\hline $7^{\circ}$ ano ou $12^{\circ}$ ano & $28(12,9)$ & & \\
\hline Técnica & $5(2,3)$ & & \\
\hline Superior & $40(18,4)$ & & \\
\hline
\end{tabular}

Pontuações obtidas pelos consulentes e pelos médicos

Na tabela 2 apresentam-se as médias, desvios-padrão e intervalos de confiança (IC) a 95\% das respostas dos consulentes para cada pergunta da JSPPPE e das respostas dos médicos para cada pergunta do questionário em espelho da JSPPPE.
Tabela 2: Médias, desvios-padrão e IC a 95\% para cada pergunta da JSPPPE e do questionário em espelho da JSPPPE, para $n=217$ consulentes

\begin{tabular}{|c|c|c|c|}
\hline & Média & $\begin{array}{l}\text { Desvio- } \\
\text { padrão }\end{array}$ & IC a $95 \%$ \\
\hline \multicolumn{4}{|l|}{ PERGUNTAS DA JSPPPE } \\
\hline 1. Consegue compreender as coisas na minha perspetiva (ver as coisas como eu as vejo) & 6,5 & 0.8 & 6,4 a 6,6 \\
\hline 2. Pergunta acerca do que está a acontecer na minha vida diária & 6,4 & 1,1 & 6,3 a 6,6 \\
\hline 3. Parece preocupado acerca de mim e da minha família & 6,5 & 1 & 6,3 a 6,6 \\
\hline 4.Compreende as minhas emoções, sentimentos e preocupações & 6,6 & 0,8 & 6,5 a 6,7 \\
\hline 5. É um médico que me compreende & 6,7 & 0,7 & 6,6 a 6,8 \\
\hline \multicolumn{4}{|l|}{ PERGUNTAS DO QUESTIONÁRIO EM ESPELHO DA JSPPPE } \\
\hline 1. Julga que consigo ver as coisas na perspetiva dele(a) & 5,8 & 0,9 & 5,7 a 5,9 \\
\hline 2. Percebe que pergunto acerca do que está a acontecer na sua vida diária & 5,8 & 0,9 & 5,6 a 5,9 \\
\hline 3. Percebeu a minha preocupação acerca dele e da sua família & 5,7 & 1,1 & 5,5 a 5,8 \\
\hline 4. Percebeu que compreendo as suas emoções, sentimentos e preocupações & 5,7 & 0,9 & 5,6 a 5,8 \\
\hline 5. Penso que julga que o(a) compreendo & 4,8 & 1,7 & 4,5 a 4,99 \\
\hline
\end{tabular}


Os valores das médias das respostas dos consulentes variam entre os 6,4 e os 6,7; a pergunta 2 ("Pergunta acerca do que está a acontecer na minha vida diária") obteve o valor mais baixo, enquanto a pergunta 5 ("É um médico que me compreende") alcançou a maior média. Já os valores das médias das respostas dos médicos variam entre os 4,8 e os 5,8 ; a pergunta 5 ("Penso que julga que o(a) compreendo") obteve o valor mais baixo, enquanto as perguntas 1 ("Julga que consigo ver as coisas na perspetiva dele(a)") e 2 ("Percebe que pergunto acerca do que está a acontecer na sua vida diária") alcançaram as maiores médias.

De forma geral, como podemos ver na tabela 3, relativamente à JSPPPE, a média de respostas dos consulentes rondou os 6,5, com mediana e moda de 7 , enquanto que em relação ao seu questionário em espelho, a média de respostas dos médicos foi de 5,5, com mediana e moda de 5 .
Tabela 3: Média, mediana, moda e desvio-padrão das perguntas dos consulentes e das dos médicos

\begin{tabular}{l|c|c} 
Média & $\begin{array}{c}\text { Perguntas dos } \\
\text { consulentes }\end{array}$ & $\begin{array}{c}\text { Perguntas dos } \\
\text { médicos }\end{array}$ \\
\hline Mediana & 6,5 & 5,5 \\
\hline Moda & 7 & 5 \\
\hline Desvio-padrão & 7 & 5 \\
\hline
\end{tabular}

De notar que todos os pares de perguntas médicoconsulente têm uma diferença de médias com valor negativo, como mostra a tabela 4; isto é, todas as perguntas respondidas pelos médicos alcançaram médias inferiores às obtidas pelos consulentes. Comprovou-se haver diferença estatisticamente significativa em todos os pares de perguntas, sempre com $p<0,001$.

Tabela 4: Diferenças de médias, desvios-padrão, IC a 95\% e valor de $\mathrm{p}$, para cada par perguntas médico-consulente

\begin{tabular}{|c|c|c|c|c|}
\hline Pares de perguntas & $\begin{array}{l}\text { Diferença } \\
\text { de médias }\end{array}$ & $\begin{array}{l}\text { Desvio- } \\
\text { padrão }\end{array}$ & IC a $95 \%$ & $p$ \\
\hline $\begin{array}{l}\text { 1. Julga que consigo ver as coisas na perspetiva dele(a) - Consegue } \\
\text { compreender as coisas na minha perspetiva (ver as coisas como eu } \\
\text { as vejo) }\end{array}$ & $-0,7$ & 1,1 & $-0,2$ a $-0,6$ & $<0,001$ \\
\hline $\begin{array}{l}\text { 2. Percebe que pergunto acerca do que está a acontecer na sua vida } \\
\text { diária - Pergunta acerca do que está a acontecer na minha vida diária }\end{array}$ & $-0,6$ & 1,2 & $-0,8$ a $-0,5$ & $<0,001$ \\
\hline $\begin{array}{l}\text { 3. Percebeu a minha preocupação acerca dele e da sua família - } \\
\text { Parece preocupado acerca de mim e da minha família }\end{array}$ & $-0,8$ & 1,4 & -1 a $-0,6$ & $<0,001$ \\
\hline $\begin{array}{l}\text { 4. Percebeu que compreendo as suas emoções, sentimentos e } \\
\text { preocupações - Compreende as minhas emoções, sentimentos e } \\
\text { preocupações }\end{array}$ & $-0,9$ & 1,2 & -1 a $-0,7$ & $<0,001$ \\
\hline $\begin{array}{l}\text { 5. Penso que julga que o(a) compreendo - É um médico que me } \\
\text { compreende }\end{array}$ & $-1,9$ & 1,8 & $-2,2 \mathrm{a}-1,7$ & $<0,001$ \\
\hline
\end{tabular}

Na tabela 5 apresentam-se valores da distribuição percentílica média para cada questionário, e na tabela 6 estão descritos as frequências e percentagens dos scores dos consulentes e os dos médicos.
Tabela 5: Distribuição percentílica média para cada questionário

\begin{tabular}{|c|c|c|}
\hline & $\begin{array}{c}\text { Perguntas dos } \\
\text { consulentes }\end{array}$ & $\begin{array}{l}\text { Perguntas dos } \\
\text { médicos }\end{array}$ \\
\hline P25 & 6,4 & 5,2 \\
\hline P50 & 7 & 5,4 \\
\hline P75 & 7 & 6 \\
\hline
\end{tabular}


Tabela 6: Frequências e percentagens dos scores dos consulentes e os dos médicos

\begin{tabular}{|c|c|c|}
\hline Scores dos consulentes & $\mathrm{n}$ & $\%$ \\
\hline 3 & 1 & 0,5 \\
\hline 4 & 1 & 0,5 \\
\hline 4,2 & 3 & 1,4 \\
\hline 4,4 & 2 & 0,9 \\
\hline 4,6 & 1 & 0,5 \\
\hline 5 & 2 & 0,9 \\
\hline 5,2 & 5 & 2,3 \\
\hline 5,4 & 5 & 2,3 \\
\hline 5,6 & 7 & 3,2 \\
\hline 5,8 & 6 & 2,8 \\
\hline 6 & 12 & 5,5 \\
\hline 6,2 & 3 & 1,4 \\
\hline 6,4 & 19 & 8,8 \\
\hline 6,6 & 19 & 8,8 \\
\hline 6,8 & 20 & 9,2 \\
\hline 7 & 111 & 51,2 \\
\hline
\end{tabular}

\begin{tabular}{|c|c|c|}
\hline Scores dos médicos & $\mathrm{n}$ & $\%$ \\
\hline 2,8 & 2 & 0,9 \\
\hline 3,2 & 2 & 0,9 \\
\hline 3,6 & 1 & 0,5 \\
\hline 3,8 & 1 & 0,5 \\
\hline 4 & 4 & 1,8 \\
\hline 4,2 & 3 & 1,4 \\
\hline 4,4 & 4 & 1,8 \\
\hline 4,6 & 6 & 2,8 \\
\hline 4,8 & 12 & 5,5 \\
\hline 5 & 18 & 8,3 \\
\hline 5,2 & 49 & 22,6 \\
\hline 5,4 & 20 & 9,2 \\
\hline 5,6 & 14 & 6,5 \\
\hline 5,8 & 11 & 5,1 \\
\hline 6 & 23 & 10,6 \\
\hline 6,2 & 6 & 2,8 \\
\hline 6,4 & 10 & 4,6 \\
\hline 6,6 & 2 & 0,9 \\
\hline 6,8 & 3 & 1,4 \\
\hline 7 & 26 & 12 \\
\hline
\end{tabular}

Para maior aperto de qualidade e conhecimento exato da realidade, consideraram-se bons os resultados pertencentes ao percentil igual ou superior ao P75, que relativamente às respostas dos consulentes será $\geq 7$ e em relação às respostas dos médicos será $\geq 6$. Deste modo, estão neste quartil 111 (51,2\%) das respostas dos consulentes e 70 (32,3\%) das respostas dos médicos.

\section{Discussão}

A maioria das consultas em MGF é de grande exigência em termos comunicacionais. ${ }^{7}$ Sendo as palavras um dos pilares da comunicação, elas podem facilitar o entendimento entre médicos e seus consulentes, esperando-se que possam tranquilizá-los e produzir efeitos terapêuticos positivos.8 Contudo, rotulando como "doença" aquilo que apenas constitui um potencial risco, tornam-se causa de iatrogenia e geram dúvidas e medos na população. ${ }^{8}$

Deste modo, cada vez mais se discute a prevenção quaternária, conceito que lança um olhar crítico sobre as atividades médicas, com ênfase na necessidade de não causar danos. ${ }^{9}$ Implica a compreensão de que a medicina está baseada na relação médico-doente, e que essa deve permanecer verdadeiramente terapêutica, respeitando a autonomia de pacientes e médicos. ${ }^{9}$

Nesse sentido, por o profissional e o consulente serem ambos intervenientes fundamentais nesta relação, é pertinente avaliar essa dualidade de perceções. Neste estudo avaliámos assim, não só a perceção dos doentes sobre a empatia dos médicos, como também a capacidade dos médicos sentirem a empatia experienciada pelos seus consulentes. Mais importante ainda, propusemo-nos a fazer, pela primeira vez, a comparação entre tais visões.

Relativamente à avaliação da perceção do consulente sobre a empatia médica, é evidente que, de forma geral, parece haver uma sensação de compreensão bastante satisfatória dos mesmos consulentes em relação aos seus médicos de família. Analisando cada item individualmente, constatou-se que a pergunta 2 ("Pergunta acerca do que está a acontecer na minha vida diária”) 
obteve a menor média $(6,4)$. Ainda que não seja óbvia a justificação para tal, uma possível explicação poderá estar na pouca disponibilidade de tempo para cada consulta, que leva o profissional a tentar direcionar a conversa para outras áreas que lhe parecem mais importantes, e que por estes resultados vemos que pode não corresponder às necessidades dos indivíduos. Por outro lado, a pergunta 5 ("É um médico que me compreende") obteve a maior média $(6,7)$, o que corrobora a existência, de uma forma geral, de uma grande satisfação dos consulentes perante os seus médicos. Apesar do elevado valor da média pontual obtida $(6,5)$, numa distribuição percentílica percebe-se que estão no melhor quartil, o $\mathrm{P} \geq 75,111$ indivíduos (51,2\%).

No que concerne à perceção dos médicos da empatia experienciada pelos seus consulentes, os profissionais parecem não conseguir julgar a real empatia sentida pelos seus utentes. A favor disso, e em contraposição à visão dos doentes, encontramos a pergunta 5 ("Penso que julga que o(a) compreendo") com a menor média $(4,8)$, podendo traduzir um constante sentimento de insatisfação e de autocrítica exagerada por parte dos médicos. Pontuações tendencialmente mais baixas dos médicos poderão traduzir, possivelmente, um de dois cenários (ou mesmo a combinação de ambos): um espírito perfecionista inerente à atividade clínica dos médicos de família, que implica uma exigência constante de si próprios, por um lado; por outro, alguma incapacidade dos consulentes em demonstrarem a sua satisfação para com os cuidados que Ihe são prestados pelos respetivos médicos, o que poderá levar os médicos a pensar que o seu trabalho não está a ser realmente reconhecido. Numa distribuição percentílica percebe-se que estão no melhor quartil, o $\mathrm{P} \geq 75$, apenas 70 médicos (32,3\%) da amostra.

Algumas limitações podem ser apontadas a este trabaIho, nomeadamente a localização geográfica restrita ao distrito de Coimbra, o tamanho da amostra (apesar de representativo da população a estudar), a realização em Unidades de Saúde Familiar e por médicos convidados. É, contudo, o preço a suportar para a sua realização em função da relativa dificuldade na adesão de médicos a trabalho acrescido à sua atividade assistencial. Além disso, há a considerar ainda o conhecimento prévio sobre o tema por parte de consulentes e médicos, bem como viéses de desejabilidade pelos consulentes e de criticismo profissional pelos médicos respondentes. A análise pelas variáveis sociodemográficas não foi objeto de análise para este trabalho sendo, por certo, interessante que trabalhos epidemiológicos posteriores venham a debruçar-se sobre tal.
Como sugestão para futuros trabalhos, poderá ser interessante repetir o estudo numa amostra maior (com mais consulentes e mais médicos incluídos), noutras zonas do país, ou mesmo em diferentes tipos de unidades de saúde (por exemplo, numa que faça consulta a um maior número de estudantes), tentando perceber se populações muito diferentes da amostra que estudámos implicariam resultados manifestamente distintos. Além disso, por não podermos descurar que um indivíduo que desenvolve uma visão positiva do seu médico durante um período relativamente longo de prestação de cuidados está mais propenso a participar nestes estudos $^{6}$, seria pertinente, futuramente, incluir uma variável que avaliasse o tempo de funcionamento da unidade de saúde e/ou o tempo de existência da lista de utentes do médico; estar-se-á à espera que um maior tempo de desenvolvimento da relação médico-doente correspondesse a maiores pontuações de empatia.

Apesar das incertezas nas justificações das diferenças de respostas entre médicos e consulentes, estamos perante resultados curiosos, que certamente implicam de nossa parte um esforço constante de melhoria e crescimento como médicos humanistas. Por esse motivo, e embora haja alguma inconsistência na literatura sobre a capacidade da empatia ser alvo de intervenção educacional ${ }^{10}$, torna-se importante dar maior ênfase ao ensino da empatia, quer no ensino pré e pós-graduado, quer na prática médica contínua, o que implicará regulares medições populacionais, considerando, inclusivamente, as suas implicações em consequências em saúde.

\section{Conclusão}

Se, por um lado, os consulentes parecem bastante satisfeitos com a relação empática desenvolvida com os seus médicos de família, por outro, os profissionais têm uma perceção não tão boa da empatia experienciada pelos seus utentes.

Em resposta à questão colocada na introdução, "Conseguem julgar os médicos a empatia sentida pelos seus consulentes?", pode-se concluir que os médicos julgam ter uma relação menos empática com os seus consulentes do que aquela que estes sentem e manifestam.

\section{Agradecimentos}

A todos os médicos e consulentes que aceitaram participar neste estudo. 
Referências Bibliográficas

1. Macedo A, Cavadas LF, Sousa M, Pires P, Santos JA, Machado A. Empathy in Family Medicine. Rev Port Clin Geral 2011;27:527-32

2. Magalhães E, Salgueira AP, Costa P, Costa MJ. Empathy in senior year and first year medical students: a cross-sectional study. BMC Med Educ 2011;11:52

3. Riess H, Kelley JM, Bailey RW, Dunn EJ, Phillips M. Empathy training for resident physicians: A randomized controlled trial of a neuroscience-informed curriculum. J Gen Intern Med 27(10):1280-6

4. Kane GC, Gotto JL, Mangione S, West S, Hojat M. Jefferson Scale of Patient's Perceptions of Physician Empathy: preliminary psychometric data. Croat Med J 2007;48:81-6

5. Hojat M, et al. Empathy in patient care: antecedents, development, measurement and outcomes. 2006;87-116

6. Hojat M, Louis DZ, Maxwell K, Markham F, Wender R, Gonnella JS. Patient perceptions of physician empathy, satisfaction with physician, interpersonal trust, and compliance. Int J Med Educ. 2010;1:83-7

7. Nunes JM. A comunicação em Contexto Clínico. Lisboa 2010;1-203

8. Norman AH. O espaço de entrecruzamento das palavras: a relação médico-paciente. Rev Bras Med Fam Comunidade. 2015;10(35):1-3

9. Jamoulle M. Quaternary prevention: first, do not harm. Rev Bras Med Fam Comunidade. 2015;10(35):1-3

10. Hojat M, Gonnella JS, Nasca TJ, Mangione S, Vergare M, Magee M. Physician mpathy: Definition, Components, Measurement, and Relationship to Gender and Specialty. Psychiatry Interpers Biol Process. 2002;159:1563-9

\section{Conflito de Interesses}

Os autores não têm conflitos de interesses a declarar para este trabalho. 
ANEXO 1. Questionário do consulente

A empatia do seu médico

Este questionário faz parte integrante da Tese de Mestrado de aluna finalista de Medicina na Faculdade de Medicina da Universidade de Coimbra. 0 estudo foi aprovado quer pela Faculdade, quer pela USF, quer pela Comissão de Ética da ARS do Centro. A sua entrega no envelope que Ihe foi dado e a deposição na caixa que está na secretaria onde se inscreveu para a consulta demonstra o seu consentimento informado.

Ninguém saberá quem respondeu nem como respondeu. Estas perguntas levam cerca de 1 minuto a responder. Caso pretenda desistir do preenchimento a qualquer altura está livre de o fazer.

Gostaríamos de saber o seu grau de concordância ou discordância em cada uma das seguintes frases acerca do seu médico que abaixo nomeamos. Por favor use a escala em sete pontos e anote a sua avaliação entre 1 e 7, fazendo um circulo no número com que mais se identifica para casa frase.

Na escala 1 significa que está em pleno desacordo e 7 que está em pleno acordo.

$$
1 \text { - } 2-3-5-5-6
$$

Discordo totalmente

Concordo totalmente

Por favor não responda segundo o que sentiu nesta consulta mas de acordo com o que tem vindo a ser a sua relação com o seu médico.
Nome do médico:

1. Consegue compreender as coisas na minha perspectiva (ver as coisas como eu as vejo)

$$
1-2-3-5
$$

2. Pergunta acerca do que está a acontecer na minha vida diária

$$
1+2-3-5
$$

3. Parece preocupado acerca de mim e da minha família

$$
1-2-3
$$

4. Compreende as minhas emoções, sentimentos e preocupações

$$
1 \text {-- } 2 \text { - } 5 \text { - } 5
$$

5. É um médico que me compreende

$$
1+2-3
$$


ANEXO 2. Questionário do médico

Questionário do Médido, para ser respondido assim que o consulente sai do gabinete

\begin{tabular}{|c|c|c|}
\hline Idade do consulente: & _ anos & \\
\hline Sexo do consulente: & $\square$ Masculino & $\square$ Feminino \\
\hline $\begin{array}{l}\text { Formação (a mais elevada que detém) } \\
\qquad \text { o consulente: }\end{array}$ & $\begin{array}{l}\square \text { Sabe ler e escrever } \\
\square 9^{\circ} \text { ano ( } 4^{\mathrm{a}} \text { classe) } \\
\left.\square 12^{\circ} \text { ano ( } 7^{\circ} \text { ano }\right)\end{array}$ & $\begin{array}{l}\square \text { Técnica } \\
\square \text { Superior }\end{array}$ \\
\hline Número de consultas no último ano: & $\begin{array}{l}\square \leq 2 \\
\square \geq 3 \text { e } \leq 5 \\
\square \geq 6\end{array}$ & \\
\hline $\begin{array}{r}\text { Número de patologias crónicas de que } \\
\text { sofre o consulente: }\end{array}$ & $\begin{array}{l}\square<2 \\
\square \geq 2\end{array}$ & \\
\hline $\begin{array}{l}\text { o Consulente tem algum problema cró- } \\
\text { nico em "Problemas Sociais" segundo } \\
\text { o Capitúlo Z da ICPC2: }\end{array}$ & $\begin{array}{l}\square \operatorname{Sim} \\
\square \text { Não }\end{array}$ & \\
\hline
\end{tabular}

Por favor responda como julga que o consulente vais responder, não segundo o que ocorreu nesta consulta mas de acordo com o que tem vindo a ser a relação com ele.

1. Julga que consigo ver as coisas na perspectiva dele(a).

$$
1-2-3-5
$$

2. Percebe que pergunto acerca do que está a acontecer na sua vida diária.

$$
1-2-3-5
$$

3. Percebe a minha preocupação acerca dele e da sua família.

$$
1 \text { - } 2 \text { - } 3 \text { - } 4 \text { - } 4 \text { - } 5
$$

4. Percebeu que compreendo as suas emoções, sentimentos e preocupações.

$$
1-2-3-5
$$

5. Penso que julga que o(a) compreendo.

$$
1 \text { - } 2 \text { - } 3 \text { - } 4 \text { - } 5 \text { - } 5
$$

